\title{
A COMPARATIVE STUDY OF DEXMEDETOMIDINE AND CLONIDINE AS AN ADJUVANT TO ROPIVACAINE IN SUPRACLAVICULAR BRACHIAL PLEXUS BLOCK
}

\author{
NAGALINGAM NATARAJAN*, GOPALAKRISHNAN KUPPUSAMY, AISHWARYA RAMANATHAN, SMITUL DAVE
}

Department of Anaesthesiology, Sri Lakshmi Narayana Institute of Medical Sciences, Pondicherry, India. Email: drnaga2k@gmail.com

Received: 03 December 2021, Revised and Accepted: 15 January 2022

ABSTRACT

Objectives: Ultrasound-guided supraclavicular brachial plexus block is the most commonly performed approach for the upper limb surgeries and perioperative pain relief. This study was conducted to compare the post-operative analgesic efficacy of dexmedetomidine and clonidine as an adjuvant to ropivacaine in supraclavicular brachial plexus block in patients undergoing upper limb surgeries.

Methods: This was a prospective, randomized, and double-blinded comparative research that included 60 ASA PS I and II patients who were scheduled for the upper limb surgery. The patients were randomized into two groups, namely, Group C and Group D, with 30 patients each. The patients in Group D were given USG-guided supraclavicular brachial plexus block with $30 \mathrm{ml}$ of $0.5 \%$ ropivacaine and dexmedetomidine $1 \mu \mathrm{g} / \mathrm{kg}$ and patients in Group C received $30 \mathrm{ml}$ of $0.5 \%$ ropivacaine and clonidine $1 \mu \mathrm{g} / \mathrm{kg}$. The patients were monitored for post-operative and interpreted by visual analog score and duration of analgesia. The Student's independent t-test was employed for comparing continuous variables. Chi-square test or Fisher's exact test, whichever is appropriate, was applied for comparing categorical variables.

Results: The mean duration of analgesia was longer and the mean consumption of rescue analgesics was lower in Group D as compared to Group C. No significant post-operative complications or local side effects related to the block were noted.

Conclusion: Dexmedetomidine prolongs the duration of sensory and motor block as well as the duration of post-operative analgesia as compared to clonidine when used as an adjuvant to ropivacaine in supraclavicular brachial plexus block.

Keywords: Supraclavicular brachial plexus block, Dexmedetomidine, Clonidine, Ropivacaine, postoperative analgesia.

(C) 2022 The Authors. Published by Innovare Academic Sciences Pvt Ltd. This is an open access article under the CC BY license (http://creativecommons.org/ licenses/by/4.0/) DOI: http://dx.doi.org/10.22159/ajpcr.2022v15i2.43752. Journal homepage: https://innovareacademics.in/journals/index.php/ajpcr

\section{INTRODUCTION}

The upper limb surgical procedures are primarily completed beneath peripheral blocks which include the brachial plexus block. There are various techniques for blocking the nerves of the brachial plexus which are classified by the level at which the needle or catheter is inserted for injecting the local anesthetic. Brachial plexus block was first performed by Halsted in 1884 [1,2]. The supraclavicular approach to brachial plexus blockade was introduced in clinical practice in Germany by Kulenkampff in 1911 [3]. The supraclavicular approach gives the most effective block for all portions of the upper extremity and is performed at the trunk level where the plexus is presented most compactly, resulting in a homogeneous spread of anesthetic drug throughout the plexus with fast onset and complete block. However, these early advantages are short-lived and limited by the relatively brief duration of action of currently available local anesthetics (LAs), which results in block resolution before the period of worst post-operative pain. Increasing the volume (dose) of LAs may additionally lengthen the duration of analgesia, but might also extend the hazard of Las systemic toxicity. Although non-stop catheter-based nerve blocks can increase post-operative analgesia, their placement calls for extra time, price, and talent. Hence, various adjuvants were used to prolong the period of analgesia of nerve blocks, for example, buprenorphine, fentanyl, magnesium, dexamethasone, midazolam, neostigmine, etc., but they all are associated with more or fewer side effects. There has always been a search for an adjuvant to the regional nerve block with drugs that prolong the duration of analgesia but with lesser adverse effects [4]. Alpha-2 adrenergic receptor agonists such as clonidine and dexmedetomidine have been the focus of interest during anesthesia for their sedative, analgesic, perioperative sympatholytic, and cardiovascular stabilizing effects with reduced anesthetic requirements [5]. Dexmedetomidine is a highly selective and specific $\alpha 2$ adrenoreceptor agonist. Dexmedetomidine has a 2:1 selectivity that is 8 times higher than clonidine, and its high specificity for the $\alpha 2$ subtype makes it more effective as a sedative and analgesic. Dexmedetomidine has also been shown to prolong the duration of block and post-operative analgesia when added to local anesthetics in various regional blocks [6]. Ropivacaine is a local anesthetic that is made from the " $\mathrm{S}$ " enantiomer of bupivacaine. Ropivacaine is less lipophilic than bupivacaine and is less likely to penetrate large myelinated motor fibers, resulting in a relatively reduced motor blockade. It is less cardiotoxic, less arrhythmogenic, and less toxic to the central nervous system than bupivacaine, and it also has intrinsic vasoconstrictor properties [7]. This study was conducted to compare and evaluate the effects of dexmedetomidine with clonidine as an adjuvant to ropivacaine in supraclavicular brachial plexus block for the upper limb surgeries in terms of onset, duration of the block, and post-operative analgesia.

\section{METHODS}

After receiving Institutional Ethics Committee clearance and registration with the Clinical Trials Registry of India (CTRI/2021/05/033667, registered on 18/05/2021), this prospective comparative study was carried out.

\section{Inclusion criteria}

The following criteria were included in the study:

- Patients in the age group of 18-65 years of both gender

- American Society of Anesthesiologists Physical Status I and II patients

- Posted for various elective upper limb procedures planned under supraclavicular brachial plexus block

- Willingness to give informed consent.

\section{Exclusion criteria}

The following criteria were excluded from the study:

- Patient refusal 
- Infection at the local site

- Hypersensitivity to local anesthetics

- Coagulation disorders

- Existing neurological disorder/nerve palsy.

After a thorough pre-operative assessment and the routine investigations were reviewed. All the patients were kept nil orally for $8 \mathrm{~h}$ before the surgery. In the operation theatre, after securing intravenous access, Lactated Ringer's solution was commenced. After establishing standard monitoring, baseline parameters such as heart rate (HR), blood pressure, electrocardiogram, and oxygen saturation $\left(\mathrm{SpO}_{2}\right)$

were recorded. All the necessary equipment and drugs needed for the administration of general anesthesia and emergency resuscitation were kept ready. USG-guided supraclavicular block was performed with 25G and 1.5-inch block needle. The patients were divided into two groups at random, each with 30 patients. For the block, patients in Groups $\mathrm{C}$ and $\mathrm{D}$ received $0.5 \%$ ropivacaine $30 \mathrm{ml}$ with clonidine $1 \mu \mathrm{g} / \mathrm{kg}$ and $0.5 \%$ ropivacaine $30 \mathrm{ml}$ with dexmedetomidine $1 \mu \mathrm{g} / \mathrm{kg}$, respectively.

Sensory and motor block assessment was done every minute till the complete effect was achieved. The onset of the sensory blockade was defined as the time interval between the injection of local anesthetic and the abolition of pinprick response. The duration of sensory block was defined as the time interval between the end of local anesthetic administration and the complete resolution of anesthesia on all four nerves (median, ulnar, radial, and musculocutaneous). The onset of a motor blockade was defined as the interval between the times of injection of a drug to development of motor weakness in the blocked limb. Duration of motor block was defined as the time interval from the onset to the recovery of complete motor function. Duration of analgesia is defined as the time interval from the onset of sensory block to the need for the first rescue analgesia. Sedation was assessed by Ramsay sedation score.

Pulse rate, mean arterial pressure, respiratory rate, $\mathrm{SpO}_{2}$, and level of sedation were recorded before giving the block, immediately after giving the block then at $5 \mathrm{~min}, 10 \mathrm{~min}, 15 \mathrm{~min}$, and $30 \mathrm{~min}$ intervals thereafter every $30 \mathrm{~min}$ till the end of surgery. Patients were observed adverse effects such as hypotension (drop in blood pressure $>20 \%$ from baseline), bradycardia (beat $<60 / \mathrm{min})$, respiratory depression $\left(\mathrm{SpO}_{2}\right.$ $<90 \%$ ) or respiratory rate $<10 / \mathrm{min}$, nausea, vomiting, hypersensitivity, and local anesthetic toxicity. Postoperatively, pulse rate, blood pressure, and respiratory rate, $\mathrm{SpO}_{2}$ level of sedation, the effect of sensory and motor block, and post-operative analgesia visual analog score (VAS) were monitored immediately after shifting the patient in the postoperative ward and then every hourly for $12 \mathrm{~h}$. Post-operative analgesia was assessed using a 10-point VAS. A $10 \mathrm{~cm}$ scaled line with 0-10 markings was shown to patients and explained that zero represents no pain and ten represents the worst pain they can imagine. The duration of analgesia was described as the time until the need for rescue analgesia. The rescue analgesic used was Inj. diclofenac sodium $1.5 \mathrm{mg} / \mathrm{kg}$ i.v. when the VAS was $>4$.

\section{Statistical analysis}

Statistical tests and analysis were done using Statistical Package for the Social Sciences (SPSS, version 20; SPSS Inc., Chicago, Illinois, USA). Normally distributed continuous data were analyzed using the student t-test. Non-normally distributed continuous data and ordinal data were analyzed using the Mann-Whitney test. Categorical data were analyzed using Chi-square or Fisher exact whichever is appropriate. $\mathrm{P}<0.05$ was considered to be significant.

\section{RESULTS}

The clinical and demographic parameters such as age, gender, weight, American Society of Anesthesiologists physical status, and duration of surgery were comparable in both the groups (Table 2) ( $>>0.05)$.

There was no statistically significant difference between the groups concerning the onset of sensory and motor blocks (Table 3)
Duration of motor and the sensory block was significantly longer in Group D than in Group C.

There was a significant decrease in pulse rate during the intra-operative period in Group D as compared to Group C $(\mathrm{p}<0.05)$. During the postoperative period, the pulse rate was comparable in both groups $(\mathrm{p}>0.05)$.

There was a significant decrease in systolic blood pressure (SBP) and diastolic blood pressure (DBP) at 30,60, and $90 \mathrm{~min}$ in Group D as compared to Group C $(\mathrm{p}<0.05)$. During the post-operative period, SBP and DBP were comparable in both groups ( $>0.05$ ). No decline in $\mathrm{SpO}_{2}$ was noted.

The sedation score was comparable throughout the study period. Post-operative analgesia was significantly prolonged in Group D as compared to Group C.

Meantime for first rescue analgesic requirement for Group D is also longer than that in Group C.

None of the side effects was noted in either of the groups.

\section{DISCUSSION}

Supraclavicular approach to brachial plexus block involves an injection of a local anesthetic around the divisions of the brachial plexus deep to the prevertebral fascia posterolateral to the subclavian artery. Due to the compact arrangement of all the three trunks of the plexus in this region, this block provides complete regional anesthesia for the surgeries on the distal arm, elbow, forearm, wrist, or hand. To induce a fast, dense, and persistent block in the brachial plexus, several adjuvants with

Table 1: Ramsay sedation score [8]

\begin{tabular}{ll}
\hline Definition & Score \\
\hline Patient is anxious and agitated or restless or both & 1 \\
Patient is cooperative, oriented, and calm & 2 \\
Patient responds to commands only & 3 \\
Patient exhibits brisk response to light glabellar tap or & 4 \\
loud auditory stimulus & \\
$\begin{array}{l}\text { Patient exhibits a sluggish response to light glabellar tap } \\
\text { or loud auditory stimulus }\end{array}$ & 5 \\
Patient exhibits no response & 6 \\
\hline
\end{tabular}

Table 2: Demographic data

\begin{tabular}{lll}
\hline Parameter & Group C & Group D \\
\hline Sex (M/F) & $17 / 13$ & $16 / 14$ \\
Age (years) & $43.46 \pm 14.80$ & $37.76 \pm 13.42$ \\
Weight (kg) & $58.26 \pm 4.67$ & $58.16 \pm 7.41$ \\
ASA Grade (I/II) & $16 / 14$ & $19 / 11$ \\
Duration of surgery (min) & $107.93 \pm 36$ & $123.7 \pm 33.73$ \\
\hline
\end{tabular}

Table 3: Onset of sensory and motor block (Mean \pm SD)

\begin{tabular}{llll}
\hline Parameter & Group C & Group D & p-value \\
\hline $\begin{array}{l}\text { Onset of sensory } \\
\text { block (min) }\end{array}$ & $9.60 \pm 0.92$ & $9.20 \pm 0.92$ & 0.09 \\
$\begin{array}{l}\text { Onset of motor block (min) } \\
\text { 12.36 } \pm 0.94\end{array}$ & $11.96 \pm 1.03$ & 0.12 \\
\hline
\end{tabular}

Table 4: Time for first rescue analgesia

\begin{tabular}{llll}
\hline Parameter & Group C Mean \pm SD & Group D Mean \pm SD & p-value \\
\hline $\begin{array}{l}\text { Meantime of } \\
\text { first rescue }\end{array}$ & $414.86 \pm 7.12$ & $605.03 \pm 9.88$ & $<0.0001$ \\
analgesic (min) & & & \\
\hline
\end{tabular}


local anesthetics agents are utilized [4,9]. In our study, $\alpha 2$ adrenergic agonists were chosen as adjuvants because of their sedative, analgesic, antihypertensive, and antiemetic actions in addition to reducing the anesthetic drugs requirement. Clonidine and dexmedetomidine are compared in this study in terms of onset and duration of sensory and motor blockade as well as post-operative analgesia in terms of first analgesic requirement. The effects of clonidine can be thought to be analgesia-mediated, vasoconstrictor effects mediated by $\alpha 2$ adrenergic receptors, attenuation of inflammatory responses, and direct effects on peripheral nerves by enhancing accessory polarization. Depends on the activity produced by the $\mathrm{Na} / \mathrm{K}$ pump during repeated stimulation, thereby increasing the threshold for activation, the action of which has the potential to slow or block conduction [10]. Dexmedetomidine is a highly selective $\alpha 2$-adrenergic receptor agonist and has 8 times higher affinity than clonidine. Because of its analgesic qualities and enhancement of local anesthetic effects as they induce hyperpolarization of nerve tissues by modifying transmembrane potential and ion conductance at locus coeruleus in the brainstem, its use reduces anesthetic and analgesic

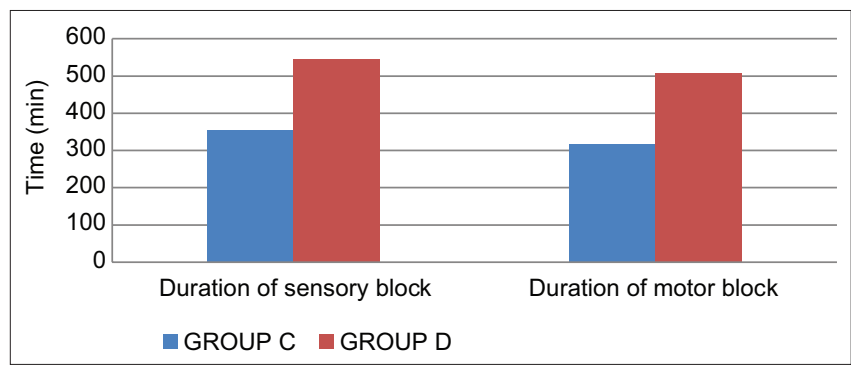

Fig. 1: Duration of sensory and motor block

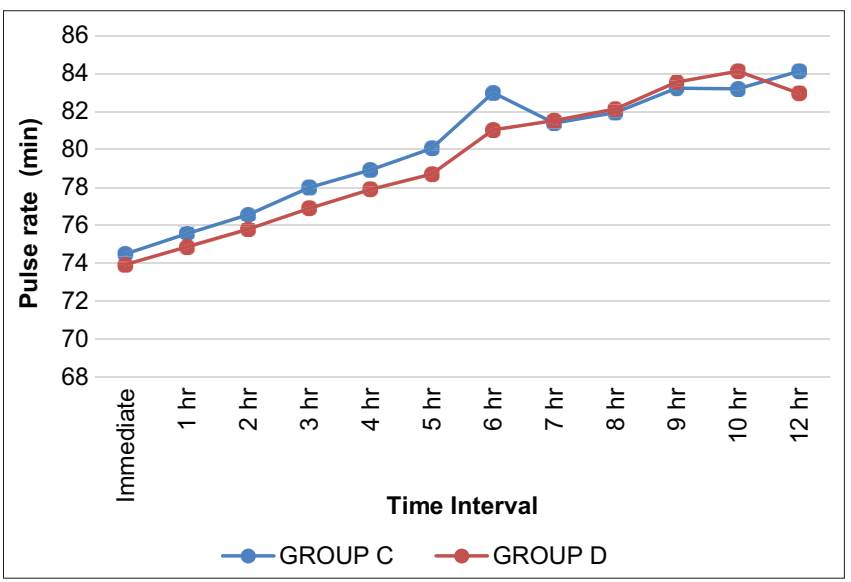

Fig. 2: Intra-operative pulse rate

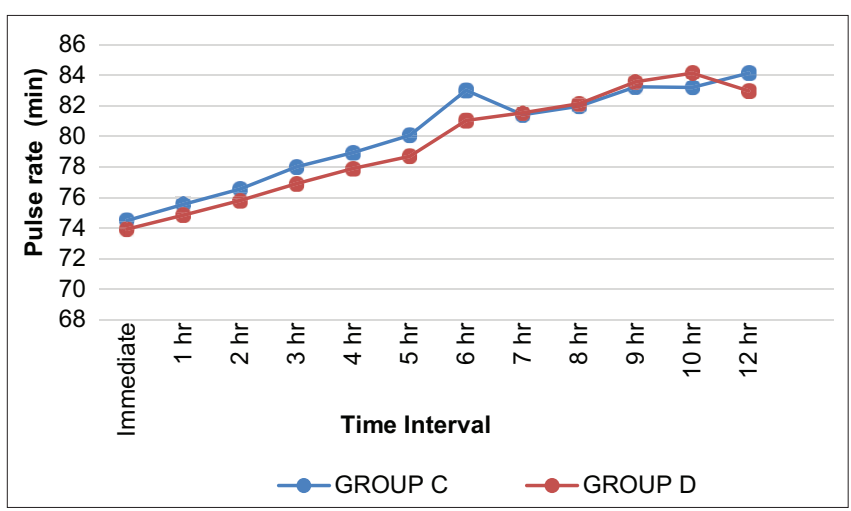

Fig. 3: Post-operative pulse rate requirements to a large amount [11]. The stable hemodynamics and the decreased oxygen demand due to enhanced sympathoadrenal stability make it a very useful pharmacologic agent. In our study, we used $0.5 \%$ ropivacaine instead of bupivacaine because it is less lipophilic and has higher cardiac stability than bupivacaine. Furthermore, increasing the concentration to $0.75 \%$ failed to improve the onset or duration of the block as per a study done by Klein et al. [12] in 1998, and $0.25 \%$ ropivacaine required frequent analgesia supplementation due to the low concentration of local anesthetic used as studied by Hickey et al. [13]. The mean time of onset of sensory and motor block in our study was earlier in Group D as compared to Group C, though the difference was not statistically significant. Our results aligned with the similar study carried out by Harshvardhana et al. [14] of dexmedetomidine and clonidine as an adjuvant to ropivacaine in supraclavicular brachial plexus. In our study, the mean duration of sensory and motor block was found to be on a higher side in Group D as compared to Group C. These differences were statistically significant. This is in concurrence with the findings of a study by Kanvee et al. [15] who compared clonidine and the use of dexmedetomidine as an adjuvant with ropivacaine in supraclavicular brachial plexus block for the upper limb surgery resulted in a considerably longer sensory and motor block in Group D. Similar findings were found in a study by Bafna et al. [16].

During the perioperative period, hemodynamic (HR, SBP, and DBP) parameters were noted at regular intervals. All the parameters were comparable between both groups. Mean pulse rate was seen to decrease in both the groups but a statistically significant decrease was noted in Group D at 30,60, 90, 120,150, and 180 min due to sedation achieved by dexmedetomidine which relieved the anxiety related to surgery and surrounding environment. Mean SBP and DBP were significantly lower than baseline in both the groups but a statistically significant decrease was noted in Group D at 30,60, and 90 min due to pain relief and cardiovascular effect of dexmedetomidine.

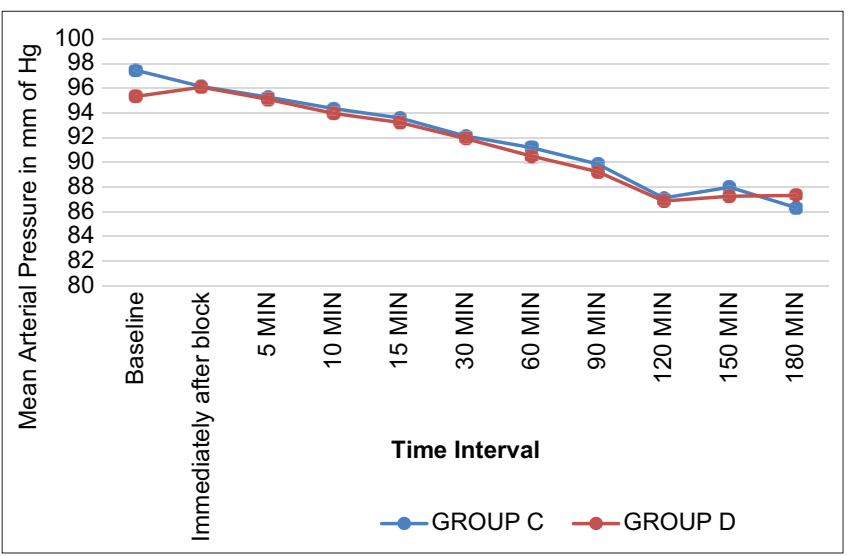

Fig. 4: Mean arterial pressure

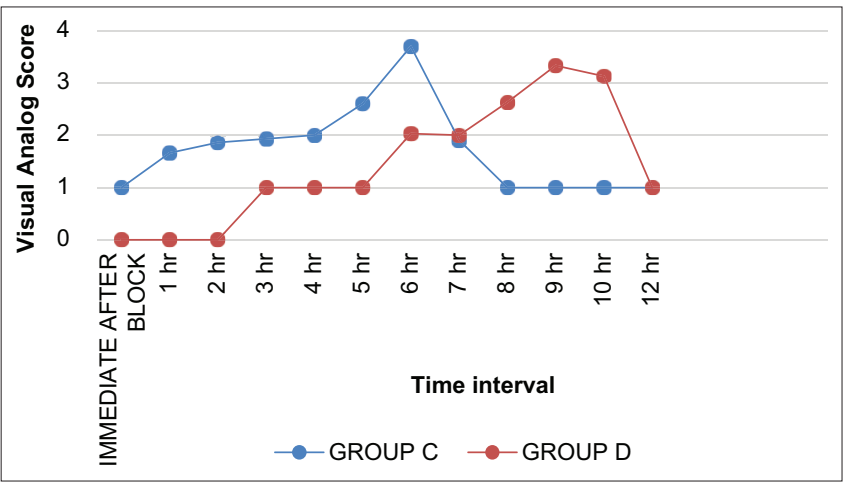

Fig. 5: Post-operative analgesia 
Our study findings were comparable and similar to a study carried out by Sebastian et al. [17] and Karthic et al. [18] conducted their study of adding dexmedetomidine and clonidine as adjuvants to levobupivacaine in supraclavicular brachial plexus block and observed HR to decrease from baseline in both his study groups but did not fall below 60 beats/ min. In our study, the duration of analgesia was recorded up to the time of need for the first rescue analgesia. The duration of pain relief was found to be significantly longer in Group D compared to Group C.

As a result of comparing dexmedetomidine and clonidine with LAs by Kanvee et al. [15] for blockade of the clavicle brachial plexus, it was found that the analgesia lasted longer in Group D than in Group C. In a study comparing dexmedetomidine and clonidine with ropivacaine in supraclavicular brachial plexus block, Sebastian et al. [17] found that dexmedetomidine produced longer post-operative analgesia in terms of delayed requirement of first rescue analgesic than clonidine.

Thus, we conclude that, in addition to analgesic properties, the added benefits of conscious sedation, hemodynamic stability, and the absence of significant side effects such as respiratory depression make dexmedetomidine and clonidine an appealing choice as an adjuvant for peripheral nerve block, with dexmedetomidine being a superior choice.

\section{CONCLUSION}

Dexmedetomidine prolongs the duration of sensory and motor block as well as the duration of post-operative analgesia as compared to clonidine when used as an adjuvant to ropivacaine in supraclavicular brachial plexus block. The added advantage of conscious sedation, hemodynamic stability, and lack of significant side effects makes dexmedetomidine captivating preference as an adjuvant for peripheral nerve block.

\section{AUTHORS CONTRIBUTION}

Dr. Nagalingam Natarajan - Design, writing the manuscript, and interpretation of data. Dr. Gopalakrishnan Kuppusamy - Concept, manuscript review, and final approval. Dr. Aishwarya Ramanathan Definition of intellectual content and literature search. Dr. Smitul Dave - Writing the manuscript, data collection, and statistical analysis.

\section{CONFLICTS OF INTEREST}

None.

\section{AUTHORS FUNDING}

No financial interest in any part of the study.

\section{ETHICAL COMMITTEE APPROVAL}

Ethical Committee and Clinical trial registry-India approval were obtained.

\section{REFERENCES}

1. Satapathy AR, Coventry DM. Axillary brachial plexus block. Anesthesiol Res Pract 2011;2011:173796.
2. Mian A, Chaudhry I, Huang R, Rizk E, Tubbs RS, Loukas M. Brachial plexus anesthesia: A review of the relevant anatomy, complications, and anatomical variations. Clin Anat 2014;27:210-21.

3. Kulenkampff D. Brachial Plexus Anaesthesia. Ann Surg 1928;87:883-91

4. AbdallahFW, Brull R. Facilitatory effects of perineural dexmedetomidine on neuraxial and peripheral nerve block: A systematic review and metaanalysis. Br J Anaesth 2013;110:915-25.

5. Kaur M, Singh PM. Current role of dexmedetomidine in clinical anesthesia and intensive care. Anesth Essays Res 2011;5:128-33.

6. Agarwal S, Aggarwal R, Gupta P. Dexmedetomidine prolongs the effect of bupivacaine in supraclavicular brachial plexus block. J Anaesthesiol Clin Pharmacol 2014;30:36-40.

7. Ali QE, Manjunatha L, Amir SH, Jamil S, Quadir A. Efficacy of clonidine as an adjuvant to ropivacaine in supraclavicular brachial plexus block: A prospective study. Indian J Anaesth 2014;58:709-13

8. Sessler CN, Grap MJ, Ramsay MA. Evaluating and monitoring analgesia and sedation in the intensive care unit. Crit Care Lond Engl 2008;12 Suppl 3:S2

9. Swami SS, Keniya VM, Ladi SD, Rao R. Comparison of dexmedetomidine and clonidine ( $\alpha 2$ agonist drugs) as an adjuvant to local anaesthesia in supraclavicular brachial plexus block: A randomised double-blind prospective study. Indian J Anaesth 2012;56:243-9.

10. Kanazi GE, Aouad MT, Jabbour-Khoury SI, Al Jazzar MD, Alameddine MM, Al-Yaman R, et al. Effect of low-dose dexmedetomidine or clonidine on the characteristics of bupivacaine spinal block. Acta Anaesthesiol Scand 2006;50:222-7.

11. Simpson D, Curran MP, Oldfield V, Keating GM. Ropivacaine: A review of its use in regional anaesthesia and acute pain management. Drugs 2005;65:2675-717.

12. Klein SM, Greengrass RA, Steele SM, D'Ercole FJ, Speer KP Gleason $\mathrm{DH}$, et al. A comparison of $0.5 \%$ bupivacaine, $0.5 \%$ ropivacaine, and $0.75 \%$ ropivacaine for interscalene brachial plexus block. Anesth Analg 1998;87:1316-9.

13. Hickey R, Rowley CL, Candido KD, Hoffman J, Ramamurthy S, Winnie AP. A comparative study of $0.25 \%$ ropivacaine and $0.25 \%$ bupivacaine for brachial plexus block. Anesth Analg 1992;75:602-6

14. Harshavardhana HS. Efficacy of dexmedetomidine compared to clonidine added to ropivacaine in supraclavicular nerve blocks: A prospective, randomized, double blind study. Int J Med Health Sci 2014;3:127-32

15. Kanvee V, Patel K, Doshi M, Mayur V, Kapil G. Comparative study of clonidine and dexmedetomidine as an adjuvant with ropivacaine in supraclavicular brachial plexus block for upper limb surgery. J Res Med Dent Sci 2015;3:127

16. Bafna U, Yadav N, Khandelwal M, Mistry T, Chatterjee CS, Sharma R. Comparison of $0.5 \%$ ropivacaine alone and in combination with clonidine in supraclavicular brachial plexus block. Indian J Pain 2015;29:41-5

17. Sebastian B, Talikoti AT, Krishnamurthy D. Attenuation of haemodynamic responses to laryngoscopy and endotracheal intubation with intravenous dexmedetomidine: A comparison between two doses. Indian J Anaesth 2017;61:48-54

18. Karthik GS, Sudheer R, Sahajananda H, Rangalakshmi S, Kumar R. Dexmedetomidine and clonidine as adjuvants to levobupivacaine in supraclavicular brachial plexus block: A comparative randomised prospective controlled study. J Evol Med Dent Sci 2015;4:3207-22. 